\title{
Keeping Cool: practicing domestic refrigeration and environmental responsibility
}

\begin{abstract}
Domestic refrigerators have become symbols of climate change in energy efficiency campaigns; they are equipment that both permits and prohibits the performance of environmental citizenship. However, little is known about how subjectivities and practices interact, particularly with regards to questions about refrigeration and domestic energy. What might those of us interested in household sustainability learn from the relationships of refrigerators, energy, subjectivities, and practices, and how these may reveal environmental responsibility? We draw on data from mixed-method qualitative research conducted with 28 households in Wollongong, Australia, and frame the analysis through social practice theory, with additional attention to subjectivity. This framing develops thinking about how refrigeration is done and how things become waste (or not), by paying closer attention to the spatial imperatives of these practices alongside how the ongoing relationships of social and material aspects of refrigeration co-constitute subjectivities. Further, our analysis advances discussions on how household practices and identities relate with public campaigns about environmental responsibility, particularly as it is constructed through 'energy efficiency'.
\end{abstract}

\section{Keywords:}

social practice theory; subjectivity; energy efficiency; household sustainability; waste; Australia

This is the author manuscript accepted for publication and has undergone full peer review but has not been through the copyediting, typesetting, pagination and proofreading process, which may lead to differences between this version and the Version of Record. Please cite this article as doi: 10.1111/1745-5871.12251

This article is protected by copyright. All rights reserved. 


\section{Introduction}

Domestic refrigeration radically transformed how food is sourced, transported, preserved, prepared, served, and discarded (Evans, 2014; Waitt and Phillips, 2015). Alongside these changes to the organisation of food came unpredictable implications arising from energy consumption — what Law and Lien (2013) might call shadow realities_-including mounting energy consumption resulting from increased numbers of fridges as well as the normalisation of the second household fridge. In the wake of contentious discourses about the fridge coming to the fore, energy policy interventions in Australia aim to repurpose refrigerators within the everyday. Such interventions aim to make the global issue of climate change legible through 'energy efficiency', referencing energy star ratings or mundane activities such as ensuring specified running temperatures (OEH, 2009; Sustainability Victoria, 2015). Refrigerators have become matters of international and household political concern. And yet, a kitchen refrigerator often goes unnoticed, normalised in its ongoing work of maintaining household routines, at least until it breaks down. In this way, refrigerators become political in how interventions deploy them as a way of reducing climate change as well as in their coconstitution of household material entanglements and subjectivities.

This paper orients around the refrigerator and household practices, energy efficiency, and related subjectivities. Well-established and important social critiques analyse environmental campaigns as neoliberal efforts that 'green' the home by individualising responsibility (Clark et al., 2007) and/or as underpinned by assumptions of 'homo economicus' (Waitt et al., 2012). Rather than retracing these critiques, we are interested in 
the intricate human-fridge-energy connections that help form environmental subjects. As Braun and Whatmore (2010, p.xxii) remind us: 'Technologies are not just objects of political deliberation; they add their own dynamics to the differential relations that constitute social and political life'. This interest requires thinking about how refrigeration devices and arrangements interact with mundane experiences and identifications. In our understanding, refrigerators may have built-in properties, but they are far from neutral, static entities; instead, refrigeration is enacted and refrigerators constitute parts of dynamic relationships that make and remake households and affect how householders think of themselves. Our analysis of the nuances of refrigeration illustrates how maintenance and monitoring practices help shape subjectivities that reflect, resist, or remain indifferent to energy efficiency campaign efforts. In so doing, our analysis demonstrates the need to think about how refrigeration becomes performed and to ask how refrigeration interacts with ideas of wasting energy in making felt multiple subjectivities.

The paper proceeds first by reviewing social sciences literature dealing with the refrigerator and then by outlining our analytic approach. The next section describes our methods and provides some detail on the households involved. The following sections analyse the subjectivities that emerge in relation to two refrigeration practices: maintaining the fridge and monitoring cooling. The conclusion considers how our framing and analysis contribute to rethinking policy interventions that target waste and climate change.

\section{Refrigeration and ways of living}


The production, supply, and use of refrigerators are deeply social. Introduced in the early 1900s, domestic refrigeration was impelled by urbanisation, global shipments of fresh produce, increasing affluence, and continuing dissatisfaction with ice-boxes. However, it was not until the 1950s that fridges were purchased in large numbers; fridges were marketed as modern, liberating, hygienic, and convenient, and were tied to post-war ideas of motherhood and home-making (see Cowan, 1976; Friedberg, 2004; Watkins, 2011). With these portrayals, the fridge became essential technology. Adoption of domestic refrigeration altered kitchen design toward scientific principles (Madison, 2007), propelled more plentiful and international economies (Isenstadt, 1998), shifted ideals of freshness and health, and extended global cold chains and economies (Freidberg, 2009). From its beginnings, domestic refrigeration has been tied up with broader ideals and movements-a site of contestation about the making of home and about food cultures.

In Australia, the Commonwealth Housing Commission endorsed refrigerators as basic equipment in the 1950s, while manufacturers pitched the refrigerator as part of the 'American way of life'. By 1955 approximately 83 per cent of Sydney households possessed a refrigerator (Dingle, 1998). Now, the refrigerator is present in 99.9 per cent of Australian households, and around one-third (33\%) use two or more fridges (ABS, 2006). Like elsewhere in the global North, refrigerators have become deeply implicated in household routines, and help sustain understandings of family, freshness, convenience, home, health, and even food security (Waitt and Phillips, 2015). Such normative reasoning about refrigerators positions them as important yet taken-for-granted features of Australian domestic life. 
Despite their transformation from magical to mundane, refrigerators are neither static nor uncontested. Possibilities of manufacturing gas-fuelled and electric-powered models were pursued with vigour in the early 1900s; yet, electric refrigerators rose to dominance (Cowan, 1985; Dauvergne, 2008). In the 1920s, concerns about the use as refrigerants of toxic gases (ammonia, methyl chloride, sulphur dioxide) led to alternatives (chlorofluorocarbons). As refrigerators became normalised, consumers turned to more aesthetic and instrumental concerns; however, energy consumption remained of some interest (see ARE, 1943). Refrigerants became controversial again in the 1980s, when the destructive effects of chlorofluorocarbons on the ozone layer were redressed through the Montreal Protocol. These days, the refrigerator has remerged as problematic - as the implications of running billions of domestic refrigerators around the clock, around the planet, become clearer.

Energy-efficient refrigerators are now positioned as key to household sustainability in government policies. For instance, the New South Wales Office for Environment and Heritage (OEH, 2017) tells website visitors that 'new appliances can cut your energy bills, improve your household and family living costs, and help protect our environment'. The argument that the ideal option for current owners of older appliances (including fridges) is disposal followed by replacement is presented as unquestionable-a 'win' for both household budgets and the environment. Energy efficiency here is about continuing consumption through new purchases, which enables governments to ignore how such efficiency might be achieved in other ways - for instance by using a smaller fridge with fewer features, even if it is older. Further, this dispose-and-replace approach follows the logic of 'lifecycle' analysis that quantifies the operational, economic, and environmental burdens of refrigerators (see for 
example Kim et al., 2006). Such an approach assumes that refrigerators are simply purchased, plugged in, switched on, and left to operate. In this scenario, sustainability is easily achieved by individuals purchasing newer technologies designed to be more efficient. No consideration is given to multiple social norms, routines, needs, or relationships. However, even among self-identified 'green consumers', purchasing a refrigerator is not a simple or isolated task; it involves complex considerations of suitability including brand, price, availability, size, energy-efficiency, and ideas of design obsolesce that inform understandings of new domestic appliances (McDonald et al., 2009). For those householders working to balance 'need' with 'thrift', purchasing a new refrigerator when the old one still functions may feel wrong, regardless of energy efficiency (Gibson et al., 2013). Indeed, energy-efficiency tends to be of lesser concern, as only 45 per cent of Australian households consider the energy rating of fridges (ABS, 2014). Moreover, the value of creating extra cooling capacity—to serve cold drinks, expand entertainment abilities, or store pet food—has encouraged the adoption of second fridges and the continued circulation of older fridges, inefficient as they may be (Schevshenko, 2002; Strandbakken, 2009; Young, 2008). As these details suggest, household decisions and practices are more complicated than lifecycle calculations allow. Energy efficiency recommendations are not always observed, even if they are known.

Despite the enthusiasm to contribute to sustainability goals, energy-efficiency campaigns often fail to achieve intended outcomes. They also tend to ignore how sustainability (or 'greening') can be multiple, and even conflictual, and neglect how such efforts might connect with other home practices and identifications. Recognizing these limitations as well as the 
need to act, we want to attend to the actual practices and meanings that shape refrigeration practices and environmental subjectivities at the household level. In undertaking our analysis, we draw inspiration from the literature on social practice theory, with additional attention to subjectivity. In doing so, we seek to include practice (and its constituent materials, skills, and ideas) without neglecting the subjectivities that emerge through working arrangements of refrigeration, or the ways in which these practices and subjectivities relate to governing efforts.

\section{Considering household refrigeration practices and subjectivities}

Researching household refrigeration can be challenging precisely because refrigeration (and fridges) have become mundane and normalised. Refrigeration can be understood, following Shove (2003), as “inconspicuous consumption” such that its everyday energy consumption is part of the taken-for-granted routines and arrangements that allow people to achieve specific tasks and roles. Shove (2004, p.1054) reminds us that people do not understand energy consumption in kilojoules; instead, 'they consume the services - heating, lighting, showing, cooking, television watching, computer interaction - that infrastructures of gas, electricity and water make possible'. As this comment suggests, much domestic energy consumption is part of taken-for-granted resource-intensive practices that (re)make everyday household living. Thus, increasing household energy efficiency requires more than new appliances or awareness-raising; it requires understanding and shifting everyday practices and subjectivities. 
Social practice theory has demonstrated that policy-making often focuses on individual behaviour driven by factors rather than on practices as dynamic, complex assemblages of human and non-human entities. Shove (2014), for instance, underscores how "behaviour change" policies misunderstand the problem by classifying and measuring household consumption as if it were a knowable and predictable machine, rather than exploring how everyday practices transform, persist, and stop. A change in focus to practices of fridgehuman-energy relationships offers a different entry point to thinking about refrigeration and sustainability - from attempts to drive individual choices to asking how 'resource intensive practices take hold in society and how they change' (Shove, 2014, p.417). Practices transform not only from contact with other practices but also from within the practice, as practitioners contest, resist, improvise, join, and abandon practices (Phillips, 2013; Warde, 2005). Thus, situating practices empirically becomes essential to understanding the dynamics of any practice, in this case allowing us to gain insight into how and why people practice refrigeration in specific ways and how these practices relate to public campaigns aimed at creating environmentally-responsible citizens.

Warde (2005) suggests that it is through practices that people come to understand the world and themselves. Despite this observation, the emergence of subjectivities and their roles within practice are less articulated within social practice theory (Birtchnell, 2012; Hargreaves, 2011). In developing a sense of the subjectivities emerging through domestic refrigeration, we find inspiration in Probyn's (2003, p.29) demand that analyses 'consider closely the material contexts which allow and delimit our individual and collective performance of selves'. Attending to what Probyn (2003, p.298) calls the 'spatial imperative 
of subjectivity' means highlighting the reciprocal, emplaced, and embodied relationship between things, self, and emotions within our practices. This conceptualisation creates a dynamic relation between places, practices, and subjectivities. As such, examining specific situated practices and related subjectivities becomes essential to understanding the dynamics of any practice. Paying attention to the situated, emotional subject whose production is ongoing as part of practice, we argue, helps reveal the reproduction of specific subject categories such as environmental citizen, home-maker, or waster, the practices that constitute them, and the house-as-home.

Conventional approaches to environmental governance often render those involved-in this case, refrigerators, people, and households_-as static, passive, and essentialised (Gibson, et al., 2013; Shove, 2014). As Marres (2012) argues, such an understanding disregards the material and normative variability of things and of their roles in private and public matters. As evidenced by the emergence of the second household fridge, for instance, energy policymakers may have thus far underestimated the extent to which fridges participate and are valued as part of home-making and socialising. We need to move beyond assumptions characterising things, practices, or people as either "good" or "bad"; rather, we need to move toward understanding 'subjects and objects not as fixed oppositions but products of their relating, as co-constituted with multiple social and material reverberations' (Hawkins, 2009, p.1).

Moreover, the conventional approach disregards how the spaces we call "home" take shape through practices tying 'the embodied self to meaningful places, and binds emotional meaning to material possessions and spaces' (Lane and Gorman-Murray, 2011, p.9). Making 
and enacting decisions about waste is a means of ordering and exerting power in the world (Edensor 2005). As such, wasting energy (or not) through practices like refrigeration can be understood as not only involved in managing private and public domains but also as a reordering of the self. As Hawkins (2006, p.31) suggests, 'it is in the space of the home, in the field of 'domestic waste education' and the massive range of campaigns geared at transforming populations' waste practices, that we can see how routines and habits are implicated in particular sorts of subjectivity ... [and] we can see the links between the broader political rationalities of waste policy and the microtechnologies of daily life'. Rather than targeting "bad" households through top-down policies with incentives to become "green" in acceptable ways, we need to explore household cultures to gain insight into how ethics and subjects become realised and justified through practices (Gibson et al., 2013; Hobson 2006). In these ways, we can refigure household refrigeration as a dynamic, everyday practice with normative variability and implications for individual and collective living.

The analytical prism we engage conceptualises household sustainability through everyday practices and subjectivities. This theoretical framing allows us to think about how things, including people, are constituted relationally in place. For us, this choice of framing means that subjectivities and practices are not predetermined or given, but rather emerge and change in the constellations of social and material interaction. Refrigeration is one example of an everyday practice underpinned by energy consumption through which people organise their lives in terms of individual, family, and work relations. And, by reframing the issue, we understand refrigeration as playing an active part in shaping social life. In the next section, 
we outline how this understanding of household sustainability informs the research methodology.

\section{Talking about and rummaging through fridges}

Our interest in refrigeration practices emerged from a project investigating household sustainability through, in part, a 2009 survey of 1,402 households in Wollongong, Australia (see Gibson et al., 2013). In relation to refrigerators, the survey indicated that 80 per cent of responding households had two or more operating fridges but that this ownership did not correlate with income or education levels. In addition, despite new features and energyefficiency recommendations that encourage replacement, surveyed households tended to keep refrigerators for years-21 per cent of primary fridges were reported as having been purchased over 10 years ago, which increased to 34 per cent in relation to the second fridge. These results prompted us to think more about living with refrigerators and about refrigeration as related to sustainability discourses, particularly around food and energy.

To research how home practices and subjectivities are co-constituted and experienced in relation to refrigeration, we employed a two-stage research design. Each phase was conducted in participants' homes, inviting people to show us their refrigerator(s) and related activities. The first phase integrated sketches with semi-structured interviews, while the second stage included follow-up interviews conducted within three weeks of the initial visit, reviews of the participants' photo diaries, and tours of their fridge(s). The interviews were guided by themes including: meanings of refrigeration; home spaces of fridges; fridge 
histories; likes/dislikes about the fridge; uses other than food storage; connections to shopping, meal planning, food storage; food spoilage and waste; refrigerator materials and technologies; fridge disposal; energy charges and initiatives to conserve energy; and pressing social concerns related to home-making. Adding sketches, diaries, and tours to the in-home interviews fostered conversations about ongoing practices that participants might not have thought to mention during a more conventional interview. For example, including sketches that mapped fridge locations prompted conversations about the siting of fridges-for energy efficiency, fitting within designated spaces, convenient access, aesthetics, and so on. Such activities also deepened conversations - for instance, about why one might retain more than one fridge, how temperature is managed, and what responses fridge alarms elicit. In sum, the interviews and activities combined to advance insights into how and why people refrigerate in specific ways and places.

Recruitment involved targeting survey participants who indicated a willingness to engage in future household sustainability research, and the use of snowballing techniques drawing on our personal networks and those of two research assistants. Information sheets were provided to potential participants and informed consent obtained as per the university ethics guidelines. Recruitment occurred over the first six months of 2013, and data collection ceased with saturation. ${ }^{1}$ Participating households numbered 28, with a total of 31 adults interviewed.

In terms of household composition, our sample comprised of: one extended family, one single professional, six share houses (four students, two professional), four couples (with no

\footnotetext{
${ }^{1}$ The data remains relevant despite the intervening period given both the consistency in government advice about how environmentally responsible domestic refrigeration is meant to be practiced in Australian households and an absence of changes to domestic refrigeration technologies or design.
} 
children at home), and 16 coupled, family households (with younger children living at home). Participants' ages ranged from the early 20 s to late 60 s, all households indicated British or European ancestry, and all considered themselves to be food secure. Employment status varied, with 17 participants working full-time, eight studying full-time, four full-time homemakers, and two having retired. Across the interviews, it was primarily women who participated; in total 23 women and eight men were interviewed. In households comprising heterosexual couples with children, the responsibilities to stock, organise, and clean refrigerators primarily fell to women with child-care responsibilities, and therefore it was these people who were interviewed (only two men participated from such households). This gender imbalance reflects the sexed, gendered, and classed cultures of parenting in Australia in which mothers still tend to be positioned as primary carers. In sum, adults who consented to participate were from relatively affluent, high-educated, hetero-normative family households.

For all participating households, domestic refrigeration was normalised to the point that everyday life without it became difficult to contemplate. All the households had at least one operating refrigerator, with 18 of the 28 households having two or more. No participants had lived without domestic refrigeration for more than a few days-for instance during a power outage or while camping — and none had thought about the role of their refrigerator in processes of home-making and/or subject-formation before our conversations. However, several people thanked us for creating the opportunity to reflect on the refrigerator as embedded in their everyday ways of living, suggesting that the research itself may have prompted some reflection upon existing practices and subjectivities. 
For analysis, each participant was assigned a pseudonym based on a gender-specific random generation program, all interviews were transcribed verbatim, and participants were invited to review their transcripts. The coding framework was built collaboratively by the authors through independent and (later) collective analysis of transcripts, photos, and sketches. For this paper, analysis focused on the human-fridge-energy nexus, and specifically on the relationship between the practices and subjectivities of refrigeration.

In the ensuing empirical sections, two significant practices drawn from the results are discussed. First, we consider how participants worked to maintain refrigerators, preventing their disposal in landfills. Second, we show how the internal temperature of fridges (and the devices that allow its monitoring) come to matter. In each section, the orienting practices are related to participants' self-presentation as environmental citizens or 'green' households. As will be shown, each of the practices relate to governmental campaigns encouraging energy efficient behaviour, but not in simple or necessarily agreeable ways.

\section{Maintaining fridges: repairing, repurposing, and gifting}

The older, less efficient fridge is often a focus of climate change campaigns targeting households. These appliances are considered inefficient, and the recommendation is that they be replaced with new models with high energy star ratings. Such disposal has been made quite straightforward — a call to your municipality, a second-hand white-goods shop, or a materials recovery centre, and your fridge will be whisked away. And, at different points in time, eligible households have qualified not only for free disposal but for additional rebates 
with fridge replacement (see for example OEH, 2017). Despite recommendations endorsing the disposal and replacement of older fridges and conveying the ease with which this end might be pursued, surveys suggest western consumers find other options more compelling. For a variety of reasons, older fridges tend to enjoy prolonged lives as a second fridge in a growing number of households (Young, 2008; Strandbakken, 2009). Further, the fact that new fridges are made primarily of plastic not metal seems to discourage discarding and replacing older working fridges, particularly among older people (Gibson et al., 2013). These trends raise questions about how multiple and older fridges become valued in households and disrupt green consumerist logics.

Among our participants, older working refrigerators were not considered disposable; rather, expressing concern about overconsumption and wasteful behaviour, our participants took care to determine what pathways these fridges followed and to consider what they could do. Fridges, in other words, became matters of domestic concern. Participants emphasised older fridges' value, asserting that they played important if varied roles in making houses-ashomes and performing subjectivities. Older fridges were donated to charity, gifted to family or friends, or repurposed as second fridges. This reuse was championed to avoid waste- $\mathrm{a}$ particular configuration of environmental responsibility, if not the one endorsed by public campaigns. Tammara (50s, homemaker, nuclear household) illustrated this sense of responsibility, speaking about her refusal to consign a working fridge to landfill:

We actually had a fridge in storage for some time and when it came out the seals weren't, [they] had been squashed and so they weren't working and my father put some sponges in to fatten them up again and then it worked fine.... We haven't thrown out 
[a fridge]. But we've given one away. But not thrown out. ... I just wouldn't throw out a fridge, I don't think, that was working. Yeah, just out of principle, I wouldn't. You could either sell it to somebody who would love it or, I don't, I just think fridges are the sort of appliances that [you] use and use until they die.

For Tammara, repairing and gifting extended the usefulness of fridges and avoided selfidentification as a 'waster'. Keeping her older, working fridge was an environmental imperative, and offered a success story of repair and of connection (finding someone who would love that fridge).

Stories of repair, reuse, and retrofitting were told with a sense of pride. Keeping older fridges, rather than throwing them away, prompted new and sometimes creative repair work, particularly by those who enjoyed performing masculinity through 'tinkering' and 'making do'. Jack (30s, professional, single household) relayed the following:

People probably think the seal is broken so you need to get a new fridge. 'Cause if the seal is broken then your shit inside gets bad. So, a set of stage handcuffs works alongside some hooks that have been attached by gaffa tape to keep the freezer closed... and to provide some interesting conversation at parties. Hoorah! As fridges fall apart, they demand not disposal but repair. In some instances, this need might encourage new relations-for example, by offering an amusing conversation piece on social occasions. Further, the repair work helped constitute 're-user' subjects as responsible citizens, entangling repairers in ethical concern about the afterlives of goods and living in a 'throwaway society'. In this way, fridges became political; prolonging the lives of working fridges was considered an act of environmental citizenship that refused unnecessary disposal—even 
if such fridges would be considered inefficient by governmental standards or public campaigns.

None of our participants who had recently acquired a new fridge assigned their old refrigerator to landfill. And only Amanda (50s, homemaker, nuclear family) spoke of participating in a government-funded buy-back scheme as 'the right thing to do':

The last fridge we had we put in the garage once we got this new one. It was a two [energy star rating] and it was going rusty. We had it as a beer fridge downstairs, but the truth of it is, they say they are very high on power usage, and so they had a fridge buyback system and we decided, 'Yes, that's the right thing to do. Let's get rid of it'.

Because we are aware that the energy usage, the energy cost, and how bad it is for the environment, if it's not necessary. ... They're supposed to be one of the most dysfunctional, high energy using things in a household, that second fridge in a garage. Following endorsements by state-sponsored energy campaigns, Amanda sacrificed her second fridge, thus restoring order to household energy consumption and constituting herself as an environmentally responsible citizen. Yet, she suggested this was only 'the right thing to do' if a second refrigerator was not necessary.

Reliance upon a second fridge in home-making practices was a theme present in many interviews. The second fridge, usually located in garages or outside (contra governmental advice), was a key feature for some households and participated in the enactment of new domestic practices and routines. Kylie (40s, homemaker, nuclear household) and Jackie (20s, homemaker, nuclear household) explained how their second refrigerators helped comprise working domestic arrangements: 
Jackie: Well, the outside fridge has mainly just drinks in it and I freeze a lot of stuff so we kind of needed a bit more freezer space. And we inherited it from my husbands' grandmother when she downsized. But it's mainly just for drinks. ... And we eat a lot outside in summer so it's easier to have it out there rather than carrying it all out there. Kylie: Drinks, dog food, and my husband loves chilli so any of his chilli stuff goes out in that one ...the kids and I don't like it and we don't want to accidentally pick something up that's got chilli on it. ... But also, it's used for when visitors come over or Christmas or when you've got extra food that there's plenty of room to put things in that freezer as well.

These comments suggested that ways of living with a second fridge had become important and even 'normal'. While Jackie emphasised ease of access and storage capacity, Kylie indicated the second fridge ensured foods were not 'contaminated' as well as available for entertaining. In both these households, among others, living without a second fridge would be troubling and require significant adjustment of routines and spaces. Keeping the second fridge is not the kind of reuse or repurposing usually considered in terms of waste; there were no examples of 'upcycling' fridges. And yet, these fridges have been reused and repurposed in the sense that they have been relocated and set to alternative tasks-like keeping drinks to facilitate celebration or leisure, for example, rather than keeping fresh food handy for kitchen preparation.

Participants showed a willingness to negotiate with older working refrigerators; leaks, spills, rust, and peeling paint were easily dealt with by placing fridges outdoors or in garages — sites where their ongoing benefits could be gained without troubling what was understood 
as 'normal' in most Australian kitchens. Millie (40s, homemaker, nuclear household) provided one example when she shared the history of two of her second fridges:

We had a little fridge out here [in the backyard] ... It was this really weird fridge that my husband's dad had at the steelworks that they used for some sort of testing and then gave to him. So, it was this bizarre looking thing. This used to be my sister's fridge and she got married and they, both her and her husband, had lived separately and so they needed to get rid of one fridge and hers didn't fit into the hole [the kitchen cut-out]. So, we got the fridge. And crazily enough, considering how ancient this thing must be, it keeps going.

As Millie revealed, retaining second fridges offered pragmatic benefits but also remade refrigerators as devices; they became entangled with emotional attachments and ongoing relations - among families and workplaces, friends and communities, even charity shops. As such, fridges became things that could not be thrown away without second thought.

This section advances the argument that the problematisation of older fridges as energy inefficient is inadequate to understanding their ongoing lives in households-whether as first or second fridges. Our participants refused to accept definitions of older fridges as problematic waste ready for discard. Instead, they chose to repair, repurpose, or gift these fridges and prolong their presence in the home. Further, it became clear that energy efficiency was not the only concern. Care for others, values of thrift and reuse, concern about intensiveresource use, as well as desires to maintain a healthy, organised household informed efforts to maintain fridges. Keeping older fridges working was not considered wasteful. Rather, these 
practices were valuable in multiple ways-including in constructing domestic and environmental subjectivities.

\section{Monitoring cooling: degrees, placements, and alarms}

Campaigns to reduce carbon emissions and food waste encourage householders to ensure refrigerator temperatures achieve maximum energy efficiency and food preservation. This mandate commonly translates into two expected behaviours: monitoring the fridge's internal temperature to confirm it stays between three and four degrees Celsius, and assure fridge doors are not unnecessarily open. We examine each of these measures in turn.

Overall, our participants were unwilling to take up the kind of centigrade surveillance championed by food safety and energy efficiency discourses. To begin, all but one of the refrigerators had dials to mediate householders' engagements with fridge temperatureindicating an interval scale (usually 1-5) rather than a degree measurement. Articulating some of the anxiety that enfolds refrigeration in food safety standards, Christina (50s, retired, nuclear household) considered herself 'lucky' to have a digital temperature display on the front of her fridge. She had adjusted her food preparation and storage to accommodate ongoing monitoring, and suggested that such shifts were unproblematic, even welcome, in that they allowed her to further her sense of being a responsible subject. For all the participants but Christina, monitoring degrees required a device additional to their refrigerator. Only one participant indicated having fleetingly used such a device, suggesting participants overall remained indifferent to such activities. Moreover, several participants indicated they were unsure about where the control dial was, or even whether their fridge had 
one. Without knowing the temperature of their fridge as a quantified measurement, the dial's mid-point tended to be adopted as the sensible option. These dials made changing the level of cooling simple, but also distanced users from using temperature as a means of understanding refrigeration as successful or not. However, this did not mean that cooling was not monitored otherwise.

The irrelevance of knowing the specific temperature did not preclude concern about fridges keeping foods sufficiently cold. Pauline (20s, homemaker, nuclear household) and Jennifer (20s, teacher, coupled household) each explained their approaches when asked about the inside temperature of their fridge:

Pauline: I don't know off hand, I'd have to have a look. I think it's set fairly high, because they [her family] like their drinks cold. I think we set it at four and the drinks weren't, they have to be icy. So [checking] it's set on about five and a half. I suppose that it's been that temperature that keeps the cheese and that nice and fresh.

Jennifer: Well, to be honest, I don't know what the internal temperature settings are. I don't think we've even changed that since the fridge came to this house. ... Basically, there hasn't been a need to change it because it seems to be working well at that temperature. I guess if everything was going off a lot sooner than we would expect we'd set the temperature to colder.

For Pauline and Jennifer, among others, refrigeration helped sustain a social order, demonstrating care for others and enabling the 'doing' of home. However, ensuring refrigeration was done well in these cases, was not about keeping a specific temperature. Knowing the temperature was extraneous. Instead, an embodied understanding of 
refrigeration was developed through food and their valued qualities—like freshness or 'going off'.

The importance of embodied understanding of food cooling was underscored through participants' discussion of potential problem zones_-places where foods froze or decayed rapidly. These refrigeration failures created moments in which participants attended to unsuccessful cooling; however, responses did not necessarily involve adjusting the fridge's temperature. Millie explained:

I don't know if it's got a temperature setting. ... I know in that fridge there are some cold spots. Like my celery is always down on the left-hand side, down a few shelves, because if I put it on the right-hand side any higher it will just freeze. So, yeah, it depends where you put things as well.

For Millie, among others, knowing temperature was unnecessary; instead, appropriate placement, learned over time, in negotiation with the fridge, allowed for foods to be kept well. This practice both shows the importance of placement and suggests a kind of practical ethics of cooling. Monitoring cooling in this way did not follow governmental advice, however, it was aimed at avoiding waste — both of food and of the effort involved. The exception to household refrigeration practices contrasting with governmental advice related to fridge door activity. Participants made sure to limit how long and how often fridge doors were opened. However, this activity did not seem to result from recent campaigns for lowcarbon futures; rather, ensuring fridge doors were opened only when necessary emerged from long-standing domestic experience. Jennifer explained the habitual qualities of such understanding: 
I think it has just become ingrained in my mind: it's bad to leave the fridge door open. Partly maybe because you're wasting electricity, but partly because you want to keep the food fresh by keeping the door closed. I guess that would, that would be like a semiconscious thing.

Jennifer indicated that an open fridge door is 'bad', making those who leave doors open for too long into wasters of food and of energy. Normalised practices of quickly shutting the fridge door, then, performed not only pragmatic ends - keeping food fresh and limiting energy bills - but also helped construct householders as responsible subjects. If cool air escaped for too long, then this identification became lost in the moment.

Each participant offered stories of surveillance—of being told and/or telling others to 'close the fridge!' These stories revealed not only the relations involved in practices, but connected refrigeration to parenting and public responsibilities. Cristina echoed other participants when she spoke of the importance of containment in closing the fridge door:

When my daughter makes things, she might open the fridge and put things on the bench and perhaps want to use the butter and put it back, or get something else out, and I'm usually saying to her: 'No, close it as you go. Keep in the cold.' ... it's letting out the cool air so you are running a fridge at a higher energy rate than it needs to be. And also the fact that if you are heating up the fridge, that's not good for the food either. And also, you've got the potential of letting in flies or bugs, I don't know, anything coming in is not good practice.

Like other participants, Cristina expressed concern for keeping the cold air within the fridge and offered several reasons for monitoring others and herself. Pauline put it most 
straightforwardly: 'I think it's just wasting the cold air and also electricity, if the door's open for too long'. It was not just a question of allowing cold air out of open doors, but of how long doors stood open. An evaluation of how long was too long was part of the surveillance, and, as Cristina suggested, this could be contested among household members.

Accommodating cold air that continually threatened to escape-and prompt wasterequired being organised in relation to what moved in and out of the fridge. Participants referred to multiple strategies employed to ensure cold air stayed contained - they grouped things together before opening the fridge to add or return things, they thought through what was needed before opening the door, and avoided pondering what they might want with the door open. This kind of ordering contributed to the process of composing refrigeration, and ensured households do not become too wasteful. Despite these concerns and ongoing practices, participants acknowledged that the fridge door sometimes failed to close. Marta (50s, homemaker, nuclear household) told us that:

I try to quickly open it and close it. If not, the food can go off. ... [But] my husband, he's got to tell me at times too when I'm in a hurry: 'You haven't shut the fridge properly'. I've taken something out and been in a hurry and something's got stuck. Nothing's perfect.

As Marta indicated, human-technology interactions are not always perfect. Even for those who conform to household disciplining, possibilities remain for disruption of practice-in this case, through hurried bodies, shifting foods, and open refrigerator doors.

Some participants' refrigerators featured alarms that sounded when the door had been left open for too long. In sounding, the alarm did not simply sound, but presented an 'expert' 
judgement of how long was too long for a fridge to be open and urged participants to respond. Participants noted how the sound affected them and their households in emotional as well as behavioural ways. Kim (30s, part-time professional, nuclear household), for instance, explained how annoyance with the alarm prompted her to check any tendency to leave the fridge door open:

You can't have it open for very long because it starts sounding like a reversing truck.

And it's the most annoying sound in the world, which is probably a good thing because when I'm unpacking groceries I open and close the fridge door rather than just leaving it open for really long periods of time.

As Andrew (50s, professional, nuclear household) reiterated: 'The fridge tells everyone to close the door so we don't have to remind each other. Open the fridge, get out everything you need at the one time, and shut it within 30 seconds. Makes you hurry up and not ponder'. However, as Kim indicated, how the device altered things was not necessarily expected. She simply opened and closed the door more often, rather than (as Andrew suggested) trying to get all the groceries in the fridge more quickly.

The sounding of the alarm created a disturbance; revealing a moment of rupture in the social order of the household. Following Ahmed (2004), affects triggered by closing, or not closing the fridge door, work to align individuals with collectives-as bodily spaces with social space. Overall, how participants welcomed the intervention of fridge alarms speaks to alleviating their responsibility of surveying fridge temperatures. Part of the responsibility for surveying and performing refrigeration was overtaken by the alarm; in-person reminders and evaluations of appropriate behaviour became unnecessary. Food and energy waste was 
avoided by prompt closing of fridge doors. In turn, this practice provided a means through which participants understood themselves as responsible in domestic and public terms. And yet, responses were not always predictable — the door may be closed simply to be opened again, the alarm may be disengaged or ignored, or people may find a game in setting the alarm off to the annoyance of others. The behaviour of properly and promptly closing fridge doors reinforced the directive from energy efficiency campaigns, but, it was about much more than that.

\section{Practicing responsible refrigeration?}

As governments and public campaigns warn of environmental consequences, 'doing the right thing' for households increasingly requires becoming low-carbon. We cannot, campaigns tell us, afford waste—whether in relation to energy, food, or some other resource. In this scenario, refrigerators have become objects of 'green' governance - a means for governments to pursue low-carbon futures through householders, who are to behave as environmental citizens through performing energy efficiency properly. Advice from Australian state governments indicate that this means households need to: possess a fridge with a high-energy star rating, keep the fridge door closed, and check its internal temperatures stay in ranges that, while preserving food, are energy efficient (OEH, 2009; Sustainability Victoria, 2015). This kind of awareness-raising reclassifies refrigerators with relatively poor energy ratings as 'bad' domestic appliances to be rejected by environmentally responsible subjects, as well as 
providing specific measures by which 'good' practices can be evaluated (for example, keeping fridge temperatures at three to four degrees Celsius).

Energy efficiency campaigns, like many environmental awareness campaigns, risk treating people merely as consumers rather than as active subjects negotiating everyday lives (Burgess et al., 2003, Malpass et al., 2007). The concentration on efficiency and policy tends to obscure the dynamic complexity of negotiating ways of living in mundane terms.

Problematised as sites of energy inefficiency, households become understood as the wasters that need to change their behaviour (Gibson et al., 2013). In contrast to such an approach, we have argued that understanding household sustainability requires attention to the coconstitution of home through everyday practices and emerging subjectivities, and how these relate with public agendas.

In this paper, we considered how expectations about how environmentally responsible refrigeration is meant to be performed relate to actual household practices and subjectivities. Our examples about maintaining fridges and monitoring cooling illustrate how householders sometimes reiterate advice offered on energy efficiency and refrigeration, but more often refuse, ignore, or work around such directives to develop their own ways of practicing practice their own ways of refrigeration and responsibility. This does not mean people do not care about waste; rather, they care differently. Keeping older refrigerators becomes, contra energy efficiency campaigns, something other than simply wasteful. Participants understood repair, reuse, and gifting as environmentally responsible in that these activities challenged the overconsumption and easy discard practices of a throwaway society. Further, they demonstrated that monitoring of cooling need not be enacted through careful measurement 
and surveillance of temperature. Instead, it may draw on food materialities, habits developed over generations, socio-technical devices like alarms, as well as environmental awareness about the problems of waste-whether of energy or food. These activities of maintenance and monitoring also provided pragmatic and emotional benefits, revealing that refrigeration offers an important means of facilitating relationships within the home as well as beyond it.

Considering these results, our research signals the importance of designing refrigerator policies that do not position Australian households as wasteful or inefficient in simple terms, but as actively engaged in constituting environmental sustainability in differentiated ways through everyday practice. How, then, might existing refrigeration practices and beliefs provide a basis for change? What kinds of intervention need to be considered? As examples, such rethinking could mean relatively short-term measures related to considering options beyond the cash economy such as support for maintenance practices. Such measures might include: facilitation of repair economies through skill workshops and tax incentives (similar to that recently introduced in Sweden); modular fridge design that allows for easy repair or replacement of parts; and rethinking house designs so that cool rooms and pantries are included, much like solar panels or rain tanks, or that smaller 'builtin' fridges become standard. And given household trends towards larger (and even multiple) fridges, government advice on the purchase of new fridges and energy efficiency might encourage not only high energy-star ratings but also smaller fridges with select features. More significant systemic changes might encompass working toward more collective cooling practices, reworking urban foodscapes and global food chains to limit refrigeration needs, and questioning food cultures that prioritise fresh, convenient foods and private household spaces. 
Both these smaller and more systemic changes would require, rather than simply blaming households, that when it comes to wasting we ask deeper questions about who is assigned and accepts responsibility, and how.

\section{References}

ABS (Australian Bureau of Statistics), 2006. Environmental impact of household energy use. Australian Social Trends, 2006. Canberra: ABS.

ABS (Australian Bureau of Statistics), 2014. Environmental issues: Energy use and conservation. Canberra: ABS.

Ahmed, S., 2004. The Cultural Politics of Emotion. Edinburgh: Edinburgh University Press. ARE (American Society of Refrigerating Engineers), 1943. Refrigerating Data Book, $5^{\text {th }}$ ed. New York: American Society of Refrigerating Engineers.

Birtchnell, T. 2012. Elites, elements and events: practice theory and scale. Journal of Transport Geography, 24, 497-502.

Braun, B. and Whatmore, S., 2010. Political Matter: Technoscience, Democracy, and Public Life. Minneapolis: University of Minnesota Press.

Burgess J., Bedford, T., Hobson, K., Davies G. and Harrison C., 2003, (Un)sustainable consumption. In Scoones, I. and Leach, M. eds., Negotiating Environmental Change, Cheltenham, UK and Northampton, MA, USA: Edward Elgar, 261-91.

Clark, N., Barnett, C., Cloke, P. and Malpass, A., 2007. The political rationalities of fair trade consumption in the United Kingdom. Politics and Society, 35(4), 538-607.

This article is protected by copyright. All rights reserved. 
Cowan, R.S., 1976. The 'industrial revolution' in the home: household technology and social change in the 20th century. Technology and Culture, 17(1), 1-23.

Cowan, R.S., 1985. How the refrigerator got its hum. In: MacKenzie D. and Wajcman J., eds., The Social Shaping of Technology. Milton Keynes: Open University Press. 202218.

Dauvergne P., 2008. The Shadows of Consumption: Consequences for the Global Environment. MIT Press, Cambridge, Massachusetts.

Dingle, T., 1998. Electrifying the kitchen in interwar Victoria. Journal of Australian Studies, 57, 119-127.

Edensor, T., 2005. Waste matter: the debris of industrial ruins and the disordering of the material world. Journal of Material Culture, 10(3), 311-332.

Evans, D. 2014. Food Waste. London, Bloomsbury.

Friedberg, S., 2009. Fresh: A Perishable History. Cambridge, MA: Harvard University Press.

Gibson, C., Farbotko, C., Gill, N., Head, L., and Waitt, G., 2013. Household Sustainability: Challenges and Dilemmas in Everyday Life. Cheltenham: Edward Elgar.

Hargreaves, T., 2011. Practice-ing behaviour change: applying social practice theory to proenvironmental behaviour change. Journal of Consumer Culture, 11(1), 79-99.

Hawkins, G., 2006. The Ethics of Waste: how we relate to rubbish. New York: Rowan and Littlefield.

Hawkins, G., 2009. The politics of bottled water. Journal of Cultural Economy, 2(1), 183195.

This article is protected by copyright. All rights reserved. 
Hobson, K., 2006. Bins, bulbs, and shower timers: on the 'techno-ethics' of sustainable living. Ethics, Place \& Environment: A Journal of Philosophy \& Geography, 9(3), 317-336.

Isenstadt, S., 1998. Visions of plenty: refrigerators in America around 1950. Journal of Design History, 11(4), 311-321.

Kim, H.C., Keoleian, G.A. and Horie, Y.A., 2006. Optimal household refrigerator replacement policy for life cycle energy, greenhouse gas emissions and cost. Energy Policy, 34, 2310-2323.

Lane, R. and Gorman-Murray, A., eds. 2011. Material Geographies of Household Sustainability. Farnham, UK: Ashgate.

Law, J. and Lien, M., 2013. Slippery: field notes on empirical ontology. Social Studies of Science, 43(3), 363-378.

Madison, D., 2007. Preserving Food without Freezing or Canning. White River Junction, USA: Chelsea Green Publishing Company.

Malpass, A., Barnett, C., Clarke N. and Cloke, P. 2007. Problematizing choice: responsible consumers and sceptical citizens. In Bevin M. and Trentmann F., eds., Governance, Consumers and Citizens. Basingstoke: Palgrave Macmillan. 231-46.

Marres, N., 2012. Material Participation: Technology, the Environment and Everyday Publics. New York: Palgrave Macmillan. 
McDonald, S., Oates, C., Thyne, M., Alevizou, P. and McMorland, LA., 2009. Comparing sustainable consumption patterns across product sectors. International Journal of Consumer Studies, 33(2), 137-145.

OEH (Office for Environment and Heritage, NSW), 2017. Appliance replacement offer. Available at: http://www.environment.nsw.gov.au/households/appliancereplacement-offer.htm

OEH (Office for Environment and Heritage, NSW), 2009. Saving Energy when Using Refrigerators and Freezers. Available at: www.energyrating.gov.au/rfuse.html Phillips, C., 2013. Saving More Than Seeds: Practices and Politics of Seed Saving. London: Routledge.

Probyn, E., 2003. The spatial imperative of subjectivity. In: K. Anderson, M. Domosh, S. Pile, N. Thrift, eds., Handbook of Cultural Geography. London: Sage Publications. 290-299.

Shevchenko, O., 2002. In the case of fire emergency: consumption, security and the meanings of durables in a transforming society. Journal of Consumer Culture, 22(2), 147-170.

Shove, E. 2003. Comfort, Cleanliness and Convenience: The Social Organization of Normality. Oxford, Berg.

Shove, E., 2004. Efficiency and consumption: technology and practice. Energy and Environment, 15(6), 1053-1065.

Shove, E., 2014. Putting practices into policy: reconfiguring questions of consumption and climate change. Contemporary Social Science, 9(4), 415-429.

This article is protected by copyright. All rights reserved. 
Strandbakken, P., 2009. Sociology fools the technician? Product durability and social constraints to eco-efficiency for refrigerators and freezers. International Journal of Consumer Studies, 33, 146-150.

Sustainability Victoria, 2015. Households: Energy efficient fridges and freezers. Available at: Www.sustainability.vic.gov.au/services-and-advice/households/energy-efficiency/athome/appliances/fridges-and-freezers

Waitt, G. and Phillips, C., 2015. Food waste and domestic refrigeration: a visceral and material approach. Social \& Cultural Geography, 17(3), 359-379.

Waitt, G., Caputi, P., Gibson, C., Farbotko, C., Head, L., Gill, N. and Stanes, E., 2012. Sustainable household capability: which households are doing the work of environmental sustainability? Australian Geographer, 43, 51-74.

Watkins, H., 2011. Beauty queen, bulletin board and browser: rescripting the refrigerator. Gender, Place and Culture, 13(2), 143-152.

Warde, A., 2005. Consumption and theories of practice. Journal of Consumer Culture, 5(2), 131-153.

Young D., 2008. Who pays for the 'beer fridge': evidence from Canada. Energy Policy, $36(2), 553-560$.

This article is protected by copyright. All rights reserved. 


\section{University Library}

\section{- M M I E E R VA A gateway to Melbourne's research publications}

Minerva Access is the Institutional Repository of The University of Melbourne

Author/s:

Phillips, C;Waitt, G

Title:

Keeping cool: practicing domestic refrigeration and environmental responsibility

Date:

2018-02-01

Citation:

Phillips, C. \& Waitt, G. (2018). Keeping cool: practicing domestic refrigeration and

environmental responsibility. GEOGRAPHICAL RESEARCH, 56 (1), pp.68-79. https:// doi.org/10.1111/1745-5871.12251.

Persistent Link:

http://hdl.handle.net/11343/293571 